\title{
Vertebral Augmentation: State of the Art
}

\author{
Amer Sebaaly ${ }^{1}$, Linda Nabhane ${ }^{2}$, Fouad Issa El Khoury ${ }^{1}$, Gaby Kreichati ${ }^{1}$, Rami El Rachkidi ${ }^{3}$ \\ ${ }^{1}$ Department of Orthopedic Surgery, Hotel Dieu de France University Hospital, Faculty of Medicine, Saint Joseph University, Beirut, Lebanon \\ ${ }^{2}$ Department of Diagnostic Radiology, Hotel Dieu de France University Hospital, Faculty of Medicine, Saint Joseph University, Beirut, Lebanon \\ ${ }^{3}$ Department of Spine Surgery, Mount Lebanon University Hospital, Faculty of Medicine, Saint Joseph University, Beirut, Lebanon
}

Osteoporotic vertebral compression fractures (OVF) are an increasing public health problem. Cement augmentation (vertebroplasty of kyphoplasty) helps stabilize painful OVF refractory to medical treatment. This stabilization is thought to improve pain and functional outcome. Vertebroplasty consists of injecting cement into a fractured vertebra using a percutaneous transpedicular approach. Balloon kyphoplasty uses an inflatable balloon prior to injecting the cement. Although kyphoplasty is associated with significant improvement of local kyphosis and less cement leakage, this does not result in long-term clinical and functional improvement. Moreover, vertebroplasty is favored by some due to the high cost of kyphoplasty. The injection of cement increases the stiffness of the fracture vertebrae. This can lead, in theory, to adjacent OVF. However, many studies found no increase of subsequent fracture when comparing medical treatment to cement augmentation. Kyphoplasty can have a protective effect due to restoration of sagittal balance.

Keywords: Kyphoplasty; Vertebroplasty; Osteoporotic fracture; Spine

\section{Introduction}

Vertebral fractures are an indicator for osteoporosis and or osteopenia [1]. As the prevalence of older and elderly individuals in the global population continues to increase, the incidence of osteoporosis will continue to rise, as will the incidence of osteoporotic vertebral fractures (OVF) [2]. OVF affects 117 per 100,000 persons; its primary and major symptom is localized back pain that can be debilitating [3]. OVF are often not associated with a fall or trauma unlike other fragility fractures [1]. More than 25\% of women 50 year of age and older will have one or more vertebral fractures by 2025 [1]. Moreover, patients with one vertebral fracture are 5-times more likely to develop another spinal fragility fracture [4]. OVF are associated with a greater and more prolonged impact on health-re- lated quality of life (HRQOL) than other fragility fractures [2].

The risk of mortality is 2 -fold higher in patients with OVF, with osteoporotic men at higher risk for mortality than women [5]. One study of a cohort of 7,233 community-dwelling older women over 65 years of age reported that women with at least one new fracture had an age-adjusted 32\% increased risk of mortality [6]. When comparing mortality from OVF to other fractures, a $25 \%$ increase in mortality risk after OVF compared to hip fractures has been described [7].

Vertebroplasty was initially described for the treatment of aggressive hemangioma of the lumbar spine [8]. Cement is injected into the vertebra via a transpedicular approach, which helps stabilize the vertebral fracture with improvement of strength and stability. Balloon kypho-

Received Jul 29, 2015; Revised Sep 11, 2015; Accepted Sep 15, 2015

Corresponding author: Amer Sebaaly

Department of Orthopedic Surgery, Hotel Dieu de France University Hospital,

Alfred Naccache Street, Achrafieh, PO Box 166830, Beirut, Lebanon

Tel: +961-3-679128, Fax: +961-1-615300, E-mail: amersebaaly@hotmail.com 
plasty creates a cavity within the vertebra by the dint of an inflatable balloon thus reducing the required injection pressure and restoring of vertebral body height (Fig. 1) [1].

In 2010, the American Academy of Orthopedic Surgeons (AAOS) evidence-based guidelines committee strongly recommended against the use of vertebroplasty and kyphoplasty as an option for the management of painful osteoporotic compression fractures [9]. This statement was based on two randomized control trials (RCTs) that were published in the New England Journal of Medicine in 2009 [10,11]. These studies were heavily criticized $[12,13]$ and since, seven other RCTs have been published.

The objective of this review is, while analyzing the evidence, to answer the following questions: (1) What is the efficacy of cement augmentation of OVF? (2) Is kyphoplasty superior to vertebroplasty in the treatment of OVF? (3) Is early fixation superior and more cost effective than delayed augmentation of vertebral osteoporotic fracture? (4) Is cement augmentation a risk factor for subsequent OVF?

\section{Efficacy of Cement Augmentation in OVF}

In 2009, Buchbinder et al. [10] published a randomized multicenter controlled trials where 78 patients were randomized to vertebroplasty or sham. No difference in matter of pain (overall, at night, at rest) and quality of life was found at 1 week or at 1,3 , or 6 months after treatment. Kallmes et al. [11] randomized 131 patients to vertebroplasty versus sham. Both groups had immediate improve- ment in disability and pain scores after the intervention. Although the two groups did not differ significantly on any secondary outcome measure at 1 month, there was a trend toward a higher rate of clinically meaningful improvement in pain in the vertebroplasty group. Hence, the AAOS based its recommendation mentioned above on these two studies. However, these two studies were heavily criticized because of the inclusion of patients with subacute and chronic fractures and so should be interpreted cautiously $[12,13]$.

Since then, seven RCT have been published, with positive results in six. The exception was a comparison of 49 patients with acute/semiacute OVF treated conservatively or with percutaneous vertebroplasty; an immediate reduction in pain was observed in the vertebroplasty group, but the results between the groups were similar at 3 and 12 months [14].

On the other hand, in the FREE trial [15], 300 patients received either kyphoplasty or optimized medical treatment. The kyphoplasty group had more rapid improvement in QOL, function, mobility, and pain. The improvement in back pain was still significantly better in the kyphoplasty group at 24 months [15]. The authors recommended balloon kyphoplasty as an early treatment option for patients with painful OVF. In the VERTOS study [16], percutaneous vertebroplasty was compared with optimal pain medication treatment in 42 patients (fracture aged more than 6 weeks and less than 6 months). The vertebroplasty group demonstrated significantly improved pain since day 1 and at 2 weeks, as well as improved quality of
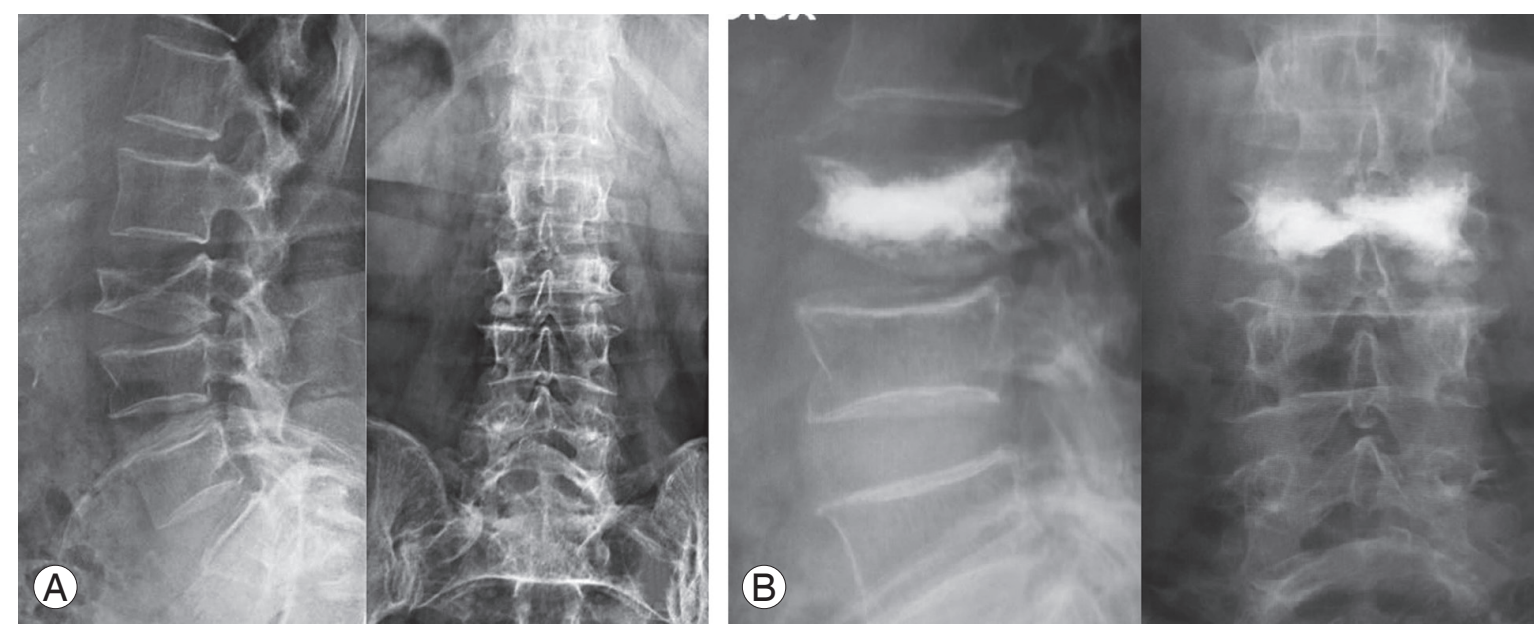

Fig. 1. A case of a 72-year-old woman who sustained a compressive vertebral fracture one month previously after a simple fall and was treated with a brace. Pain persisted and an X-ray revealed complete loss of vertebral height (A). Kyphoplasty was performed and $X$-ray shows restitution of vertebral height (B). 
life [16]. In the VERTOS II study [17], 202 patients over 50 years of age with acute OVF were randomized to vertebroplasty or optimal conservative treatment. Pain relief was immediate after vertebroplasty and was sustained for 1 year, and was significantly better than that achieved with conservative treatment. The authors also reported a gain of 30,000 Euro per quality adjusted life year (QALY) [17]. Farrokhi et al. [18] randomized 82 patients to percutaneous vertebroplasty or optimal medical management. The vertebroplasty group had significant improvement of QOL at all evaluations ( 3 weeks, 3 months, 6 months, 1 year, 18 months, and 2 years). However, pain improvement was limited to the first three evaluations. Blasco et al. [19] randomized 125 patients to vertebroplasty or optimal medical treatment. Both groups showed significant improvement in VAS scores at all time points, but at 2 months there was greater improvement in the vertebroplasty group. QOL was superior in the vertebroplasty group at all time points, whereas the control subject group did not have an improvement until the 6-month follow-up [19]. The last RCT compared balloon kyphoplasty to non-surgical management in 300 patients. The kyphoplasty group had greater improvements in the QOL across the 24-month followup period compared with nonsurgical therapy. Back pain was statistically less in the kyphoplasty throughout followup [20]. When all this data was compiled into a metaanalysis, the VAS mean difference was 0.73 for early $(<12$ weeks) and 0.58 for late time points (6-12 months), favoring vertebroplasty $(p<0.001)$. The functional outcomes at early and late time points were statistically significant, as well as the superiority of the HRQOL.

On the other hand, cement volume seems to affect the outcome of the procedure. In fact, Roder et al. [21] found that cement volume correlated positively with pain relief with lower cement filling volumes contributing to inferior postoperative outcomes and recommended a volume of more than $4.5 \mathrm{~mL}$ to achieve clinical efficacy. Even more, Martinčič et al. [22] proved in a cadaveric study that cement volume correlated with compressive stiffness of the vertebra and recommended the filling of a fractured thoracolumbar vertebra fracture with a minimum of 4-6 $\mathrm{mL}$ of cement volume. However, higher volumes would be associated with higher cement extrusion, especially in vertebroplasty. In fact, Ren et al. [23] found in a multivariate model of 171 vertebral bodies that cement volume and vertebral wall incompetence are significant predictors for cement leakage in kyphoplasty. On the other hand,
Kaufmann et al. [24] and Roder et al. [21] found no relationship between cement volume and extravasation. In short, while there is no definitive evidence to support a specific volume of cement to be injected, a cement volume of 5-6 $\mathrm{mL}$ seems to be a reasonable choice.

All this evidence favors cement augmentation in the treatment of symptomatic OVF [25]. Conclusions should be cautiously drawn as the results were heterogeneous and with a high likelihood of bias, because most of these studies were sponsored by industry [1].

\section{Kyphoplasty versus Vertebroplasty}

When performing a kyphoplasty, a balloon is used to create a cavity in the fractured vertebra thus reducing the kyphosis and the injection pressure. It has the theoretical advantages of improving the kyphosis at the fractured level and reducing the injection pressure, which limits cement leakage [1]. Nineteen studies compared the efficacy and the safety profile of kyphoplasty compared to vertebroplasty [26] but only two RCTs compared the efficacy of these techniques $[27,28]$.

In the first RCT, 100 patients with OVF received vertebroplasty or kyphoplasty. Vertebral body height and kyphotic wedge angle was significantly better in the kyphoplasty group. Pain scores did not differ significantly between the treatment groups [27]. A meta-analysis of the randomized and non-randomized controlled trials compared 832 patients between kyphoplasty and vertebroplasty. Vertebroplasty was more effective for pain relief in the short-term (no more than 7 days), while kyphoplasty was superior for intermediate-term (approximately 3 months) functional improvement. No difference was shown between the two in long-term pain relief or functional improvement [29]. When recent data is added, the 1081 patients showed no difference in pain scores at short-term follow-up, but a favorable result for kyphoplasty for intermediate pain scores was evident [30]. Furthermore, there was no difference in operative time, but significant improvements were evident in local kyphosis and the anterior height of the vertebral body [31]. However, no differences in QOL scores were observed [30]. Thus no clinical difference was found, albeit the significant improvement of kyphosis.

Cement leakage remains a significant complication from vertebroplasty and kyphoplasty procedures. Cement leakage into the vertebral veins or spinal canal could 
lead to serious clinical complications [1]. Vogl et al. [28] randomized 77 patients with painful OVF to kyphoplasty or vertebroplasty. Kyphoplasty was associated with significantly reduced number of levels with leaks and total number of leaks per level. This finding was confirmed by two recent meta-analyses that documented a risk ratio of cement leakage in kyphoplasty compared to vertebroplasty of 0.65 (range, 0.49-0.89) [26,31]. However, when separating the leakage into two groups- "at risk" disc space and "the safe" paravertebral space-no difference in cement leakage was found in the disc space, but cement leaked more in the paravertebral space in vertebroplasty [26]. This finding could be explained by the higher viscosity of cement in kyphoplasty due to its lower injection pressure.

To be considered cost effective, an intervention should provide a cost per quality-adjusted life-year (QALY) of less than 50,000 dollars [1]. When analyzing cost effectiveness of cement augmentation, vertebroplasty was found to cost 30,000 euro per QALY gain [17]. Even more, a recent study showed ballon kyphoplasty to be a cost-effective strategy for the treatment of patients hospitalized with acute OVF compared to vertebroplasty and medical treatment [32]. In contrast, an analysis of the cost-effectiveness of balloon kyphoplasty compared with standard medical treatment found the cost per QALY gained 92,154 euros [33]. A recent systematic review could not draw a definitive conclusion on the cost-effectiveness of vertebroplasty or kyphoplasty [34]. Thus, owing to the higher cost of the kyphotic balloon procedure, the authors recommend vertebroplasty over kyphoplasty for the treatment of OVF [27].

\section{Early versus Delayed Augmentation of OVF}

Early vertebroplasty for acute OVF has gained popularity in recent years. A recent study compared a nonrandomized model of early and delayed vertebroplasty (at least 2 weeks after the onset of fracture) for acute OVF at the thoracolumbar junction [35]. The authors found no difference in the final clinical outcome in term of VAS, Oswestry Disability Index, and Odom's criteria, as well as in final vertebral body collapse and segmental kyphosis. The major finding in this study is that immediate improvement of the VAS after vertebroplasty was greater in the early compared to the delayed group. Cement leakage was less in the early group. This is the only published data comparing the early versus delayed vertebroplasty for acute OVF, hence the need of RCTs.

\section{Cement Augmentation and Subsequent OVF}

The injection of cement in the fractured vertebra has been implicated in significant changes in vertebral strength, vertebral shape, and consequently increased strain on the adjacent osteoporotic fracture [4]. New fracture can reflect progression of osteoporotic disease or can be a direct consequence of the surgical treatment. When evaluating the results of the VERTOS II study, the incidence of new OVF in patients was not different after vertebroplasty compared with conservative therapy in the first year of follow-up. The only risk factor for the occurrence of new OVF was the number of OVFs at baseline [36]. Compilation and analysis of the data from the 13 studies $(n=2,551)$ revealed a similar incidence of overall vertebral fracture in the vertebroplasty group compared to those receiving conservative therapy [4]. In a subgroup analysis, no difference was found to adjacent OVF [4]. Another metaanalysis found no increase of adjacent or overall OVF after vertebroplasty [37]. When comparing kyphoplasty to vertebroplasty, no difference in the incidence of OVF was found $[4,37]$.

One special situation is when a vertebra is sandwiched between two augmented OVFs. This situation increases the strain on the middle vertebra. In a study that randomized 290 patients with 363 OVFs with a total of 27 sandwich situations to vertebroplasty or conservative treatment, the same incidence of fracture was found in the vertebroplasty and conservative treatment groups at a mean follow-up of 4 years [38]. Sandwiching did not have any effect on subsequent fracture incidence. The only notable finding was the earlier incidence of an OVF in the vertebroplasty group.

Even though cement augmentation increases the stiffness of the augmented vertebra, the incidence of new vertebral fracture is not increased $[4,37,38]$. Even more, a protective effect of kyphoplasty has been reported [36]. This finding could be explained by the restoration of the sagittal profile and vertebral height with kyphoplasty [39].

\section{Indications and Contraindications for Vertebroplasty and Kyphoplasty}

In 2010, Röllinghoff et al. [40] published a consensus among 160 expert practitioners on the indications and 
contra-indications of cement augmentation in OVF. Indications were: (1) painful osteoporotic OVF that does not improve with 2-3 weeks of nonsurgical care, (2) hospitalization as a result of painful OVF, (3) painful pathologic fracture, (4) aggressive hemangioma, and (5) Kümmell disease. Absolute contraindications were: (1) asymptomatic fractures, (2) history of vertebral body osteomyelitis, (3) allergy to bone fillers, and (4) irreversible coagulopathy. Relative contraindications were: (1) presence of radiculopathy, (2) bone retropulsion against neural structures, (3) $>70 \%$ collapse of vertebral body height, and (4) multiple pathologic fractures.

When cement augmentation is indicated, evidence does not help in the choice between kyphoplasty and vertebroplasty. Cement augmentation is not recommended when the OVF is less than 1 month old [41], even with recent evidence of better pain management with early ( $<2$ days) vertebroplasty [35]. If pain persists after one month of medical management cement augmentation is indicated. The percentage of compression of the vertebral body determines whether to use vertebroplasty or kyphoplasty. OVF with a collapse $<30 \%$ are an indication for vertebroplasty whereas OVF with a collapse $>30 \%$ are an indication of kyphoplasty. When more than 3 months have passed since the fracture incidence, and when cement augmentation is indicated, only vertebroplasty could be used, as kyphoplasty does not offer the kyphosis correction anymore.

\section{Conclusions}

OVF is a rising problem affecting mainly the older population. This review has highlighted the superiority of cement augmentation over an optimal conservative treatment for OVF. Kyphoplasty is associated with significant improvement of local kyphosis and less cement leakage without any difference in long-term pain or functional outcome. Cement augmentation is not associated with higher incidence of subsequent OVF. The percentage of compression of the vertebral body and the age of the fracture can determine whether to use kyphoplasty or vertebroplasty.

\section{Conflict of Interest}

No potential conflict of interest relevant to this article was reported.

\section{References}

1. Savage JW, Schroeder GD, Anderson PA. Vertebroplasty and kyphoplasty for the treatment of osteoporotic vertebral compression fractures. J Am Acad Orthop Surg 2014;22:653-64.

2. Rostom S, Allali F, Bennani L, Abouqal R, HajjajHassouni N. The prevalence of vertebral fractures and health-related quality of life in postmenopausal women. Rheumatol Int 2012;32:971-80.

3. Melton LJ 3rd, Kallmes DF. Epidemiology of vertebral fractures: implications for vertebral augmentation. Acad Radiol 2006;13:538-45.

4. Han SL, Wan SL, Li QT, et al. Is vertebroplasty a risk factor for subsequent vertebral fracture, meta-analysis of published evidence? Osteoporos Int 2015;26: 113-22.

5. Lau E, Ong K, Kurtz S, Schmier J, Edidin A. Mortality following the diagnosis of a vertebral compression fracture in the Medicare population. J Bone Joint Surg Am 2008;90:1479-86.

6. Kado DM, Duong T, Stone KL, et al. Incident vertebral fractures and mortality in older women: a prospective study. Osteoporos Int 2003;14:589-94.

7. Cauley JA, Thompson DE, Ensrud KC, Scott JC, Black D. Risk of mortality following clinical fractures. Osteoporos Int 2000;11:556-61.

8. Galibert P, Deramond H, Rosat P, Le Gars D. Preliminary note on the treatment of vertebral angioma by percutaneous acrylic vertebroplasty. Neurochirurgie 1987;33:166-8.

9. Esses SI, McGuire R, Jenkins J, et al. The treatment of symptomatic osteoporotic spinal compression fractures. J Am Acad Orthop Surg 2011;19:176-82.

10. Buchbinder R, Osborne RH, Ebeling PR, et al. A randomized trial of vertebroplasty for painful osteoporotic vertebral fractures. N Engl J Med 2009;361:55768.

11. Kallmes DF, Comstock BA, Heagerty PJ, et al. A randomized trial of vertebroplasty for osteoporotic spinal fractures. N Engl J Med 2009;361:569-79.

12. Chen L, Black C, Hirsch JA, Beall D, Munk P, Murphy K. Vertebroplasty trials: the medium is the message. J Vasc Interv Radiol 2014;25:323-5.

13. Aebi M. Vertebroplasty: about sense and nonsense of uncontrolled "controlled randomized prospective trials”. Eur Spine J 2009;18:1247-8. 
14. Rousing R, Hansen KL, Andersen MO, Jespersen SM, Thomsen K, Lauritsen JM. Twelve-months follow-up in forty-nine patients with acute/semiacute osteoporotic vertebral fractures treated conservatively or with percutaneous vertebroplasty: a clinical randomized study. Spine (Phila Pa 1976) 2010;35:478-82.

15. Wardlaw D, Cummings SR, Van Meirhaeghe J, et al. Efficacy and safety of balloon kyphoplasty compared with non-surgical care for vertebral compression fracture (FREE): a randomised controlled trial. Lancet 2009;373:1016-24.

16. Voormolen MH, Mali WP, Lohle PN, et al. Percutaneous vertebroplasty compared with optimal pain medication treatment: short-term clinical outcome of patients with subacute or chronic painful osteoporotic vertebral compression fractures. The VERTOS study. AJNR Am J Neuroradiol 2007;28:555-60.

17. Klazen CA, Lohle PN, de Vries J, et al. Vertebroplasty versus conservative treatment in acute osteoporotic vertebral compression fractures (Vertos II): an openlabel randomised trial. Lancet 2010;376:1085-92.

18. Farrokhi MR, Alibai E, Maghami Z. Randomized controlled trial of percutaneous vertebroplasty versus optimal medical management for the relief of pain and disability in acute osteoporotic vertebral compression fractures. J Neurosurg Spine 2011;14:561-9.

19. Blasco J, Martinez-Ferrer A, Macho J, et al. Effect of vertebroplasty on pain relief, quality of life, and the incidence of new vertebral fractures: a 12-month randomized follow-up, controlled trial. J Bone Miner Res 2012;27:1159-66.

20. Boonen S, Van Meirhaeghe J, Bastian L, et al. Balloon kyphoplasty for the treatment of acute vertebral compression fractures: 2-year results from a randomized trial. J Bone Miner Res 2011;26:1627-37.

21. Roder C, Boszczyk B, Perler G, Aghayev E, Kulling F, Maestretti G. Cement volume is the most important modifiable predictor for pain relief in BKP: results from SWISSspine, a nationwide registry. Eur Spine J 2013;22:2241-8.

22. Martincic D, Brojan M, Kosel F, et al. Minimum cement volume for vertebroplasty. Int Orthop 2015;39:727-33.

23. Ren H, Shen Y, Zhang YZ, et al. Correlative factor analysis on the complications resulting from cement leakage after percutaneous kyphoplasty in the treatment of osteoporotic vertebral compression fracture.
J Spinal Disord Tech 2010;23:e9-15.

24. Kaufmann TJ, Trout AT, Kallmes DF. The effects of cement volume on clinical outcomes of percutaneous vertebroplasty. AJNR Am J Neuroradiol 2006;27: 1933-7.

25. Anderson PA, Froyshteter AB, Tontz WL Jr. Metaanalysis of vertebral augmentation compared with conservative treatment for osteoporotic spinal fractures. J Bone Miner Res 2013;28:372-82.

26. Xiao H, Yang J, Feng X, et al. Comparing complications of vertebroplasty and kyphoplasty for treating osteoporotic vertebral compression fractures: a metaanalysis of the randomized and non-randomized controlled studies. Eur J Orthop Surg Traumatol 2015;25 Suppl 1:S77-85.

27. Liu JT, Liao WJ, Tan WC, et al. Balloon kyphoplasty versus vertebroplasty for treatment of osteoporotic vertebral compression fracture: a prospective, comparative, and randomized clinical study. Osteoporos Int 2010;21:359-64.

28. Vogl TJ, Pflugmacher R, Hierholzer J, et al. Cement directed kyphoplasty reduces cement leakage as compared with vertebroplasty: results of a controlled, randomized trial. Spine (Phila Pa 1976) 2013;38:1730-6.

29. Han S, Wan S, Ning L, Tong Y, Zhang J, Fan S. Percutaneous vertebroplasty versus balloon kyphoplasty for treatment of osteoporotic vertebral compression fracture: a meta-analysis of randomised and non-randomised controlled trials. Int Orthop 2011;35:134958.

30. Ma XL, Xing D, Ma JX, Xu WG, Wang J, Chen Y. Balloon kyphoplasty versus percutaneous vertebroplasty in treating osteoporotic vertebral compression fracture: grading the evidence through a systematic review and meta-analysis. Eur Spine J 2012;21:184459.

31. Xing D, Ma JX, Ma XL, et al. A meta-analysis of balloon kyphoplasty compared to percutaneous vertebroplasty for treating osteoporotic vertebral compression fractures. J Clin Neurosci 2013;20:795-803.

32. Svedbom A, Alvares L, Cooper C, Marsh D, Strom O. Balloon kyphoplasty compared to vertebroplasty and nonsurgical management in patients hospitalised with acute osteoporotic vertebral compression fracture: a UK cost-effectiveness analysis. Osteoporos Int 2013;24:355-67.

33. Fritzell P, Ohlin A, Borgstrom F. Cost-effectiveness of 
balloon kyphoplasty versus standard medical treatment in patients with osteoporotic vertebral compression fracture: a Swedish multicenter randomized controlled trial with 2-year follow-up. Spine (Phila Pa 1976) 2011;36:2243-51.

34. Stevenson M, Gomersall T, Lloyd Jones M, et al. Percutaneous vertebroplasty and percutaneous balloon kyphoplasty for the treatment of osteoporotic vertebral fractures: a systematic review and cost-effectiveness analysis. Health Technol Assess 2014;18:1-290.

35. Son S, Lee SG, Kim WK, Park CW, Yoo CJ. Early Vertebroplasty versus delayed vertebroplasty for acute osteoporotic compression fracture: are the results of the two surgical strategies the same? J Korean Neurosurg Soc 2014;56:211-7.

36. Klazen CA, Venmans A, de Vries J, et al. Percutaneous vertebroplasty is not a risk factor for new osteoporotic compression fractures: results from VERTOS II. AJNR Am J Neuroradiol 2010;31:1447-50.

37. Zhang YZ, Kong LD, Cao JM, Ding WY, Shen Y. In- cidence of subsequent vertebral body fractures after vertebroplasty. J Clin Neurosci 2014;21:1292-7.

38. Yi X, Lu H, Tian F, et al. Recompression in new levels after percutaneous vertebroplasty and kyphoplasty compared with conservative treatment. Arch Orthop Trauma Surg 2014;134:21-30.

39. Baek SW, Kim C, Chang H. The relationship between the spinopelvic balance and the incidence of adjacent vertebral fractures following percutaneous vertebroplasty. Osteoporos Int 2015;26:1507-13.

40. Rollinghoff M, Zarghooni K, Schluter-Brust K, et al. Indications and contraindications for vertebroplasty and kyphoplasty. Arch Orthop Trauma Surg 2010;130:765-74.

41. Lovi A, Teli M, Ortolina A, Costa F, Fornari M, Brayda-Bruno M. Vertebroplasty and kyphoplasty: complementary techniques for the treatment of painful osteoporotic vertebral compression fractures: a prospective non-randomised study on 154 patients. Eur Spine J 2009;18 Suppl 1:95-101. 